\title{
Towards eHealth to support the health journey of headache patients: a scoping review
}

\author{
Daniëlle L. van de Graaf ${ }^{1}$ · Guus G. Schoonman ${ }^{2}$ - Mirela Habibović $\dot{c}^{3,4}$ · Steffen C. Pauws ${ }^{5,6}$
}

Received: 1 May 2020 / Revised: 4 June 2020 / Accepted: 5 June 2020 / Published online: 11 June 2020

(c) The Author(s) 2020

\begin{abstract}
Objective The aim of this study is to (1) review the digital health tools that have been used in headache studies, and (2) discuss the effectivity and reliability of these tools.

Background Many headache patients travel a long and troublesome journey from first symptoms until a meaningful care plan. eHealth, mHealth, and digital therapeutic modalities have been advocated as the way forward to improve patient care. Method Online databases PubMed, Cinahl, and PsycINFO were searched using a predefined search query. A data extraction form was used to gather relevant data elements from the selected papers.

Results A total of 39 studies were selected. The studies included 94,127 participants. The majority of studies focused on diaries $(N=27$ out of 39). Digital (cognitive) behavioral therapy were also quite common ( $N=7$ out of 39$)$. Other digital health tool categories were tele-consultations, telemonitoring and patient portals.

Conclusion Many digital health tools for headache patients regarding diaries and behavioral/therapeutical treatment are described in scientific research with limited information on effectivity and reliability. Scientific knowledge with regard to other categories such as tele-consultations, patient portals, telemonitoring including medication adherence, online information resources, wearable, symptom checkers, digital peer support is still scarce or missing.
\end{abstract}

Keywords Migraine $\cdot$ Tension-type headache $\cdot$ Cluster headache $\cdot$ Digital health tool $\cdot$ mHealth

\section{Introduction}

Headache is a common cause of disability. In a large population-based study of 16,256 people, approximately $20 \%$ reported experiencing headache on more than 5 days per month and $3.7 \%$ on more than 15 days per month [1]. Many headache patients travel a long and troublesome journey

Daniëlle L. van de Graaf

d.1.vdgraaf@tilburguniversity.edu

1 Department of TSDH Research Center, Tilburg University, Tilburg, The Netherlands

2 Department of Neurology, Elizabeth-TweeSteden Hospital, Tilburg, The Netherlands

3 Department of Medical and Clinical Psychology, Tilburg University, Tilburg, The Netherlands

4 Department of Cardiology, Elizabeth-TweeSteden Hospital, Tilburg, The Netherlands

5 TiCC-Tilburg University, Tilburg, The Netherlands

6 Philips Research, Healthcare, Eindhoven, The Netherlands from first symptoms until a meaningful care plan including treatment. Ideally, a care plan should include a clear diagnosis, a treatment protocol, and a coaching strategy [2]. However, to come up with an effective care plan, important challenges that are associated with patients' health journey must be overcome. These challenges include: (a) incorrect self-care by patient, (b) misdiagnosis or incomplete diagnosis by healthcare professionals, (c) waiting times in healthcare and doctor delays, (d) incorrect or inappropriate therapy, (d) under/over medication, (e) incorrect management of co-morbidities, (f) miscommunication between patient and specialists, (g) lack of guidance, and (h) misconceptions or misunderstandings from peers or work setting $[3,4]$.

With the pressing demand on the health care system, a shift towards the use of eHealth, mHealth, and digital therapeutic modalities has been advocated as the way forward to improve patient care and provide support to larger (underserved) groups of patients $[5,6]$. We define eHealth as an abbreviation for electronic health to refer to the use of digital information and services in communication over the Internet to support and improve health or healthcare delivery to 
individuals. mHealth is the abbreviation for mobile health with refers to the use of mostly personal mobile or wearable electronic devices like smartphones, tablets, and wearables in health and healthcare delivery. If evidence-based treatment interventions are rendered to diagnosed patients via high-quality medically approved eHealth or mHealth software technology, we have reserved the specific but recent term of digital therapeutics or, short named, DTx [7]. As compared to traditional approaches, where patients have to visit the out-patient clinic for diagnosis and treatment, eHealth enabled care is about reducing the number of inperson visits while at the same time getting more (accurate) information from the patients via remote devices [8]. If properly validated on safety and outcome, digital form of consult and/or treatment could make care delivery safer, decrease patient burden, be more cost-efficient and more effective in patient outcome. For instance, within the mental healthcare, behavioral eHealth interventions have shown promising results which are comparable to traditional face-to-face treatment effects $[9,10]$. In addition, studies also show that eHealth approaches are very well accepted by patients and could be implemented in the clinical practice [11]. A systematic review concluded that eHealth to remotely monitor patients with the long-term condition of heart failure reduced all-cause mortality by $34 \%$ and hospitalization by $21 \%$, but that there are still mixed and heterogeneous effects for eHealth for heart failure across studies [12].

With respect to headache treatment and management, the use of eHealth applications or digital therapeutics has also been advocated. This has resulted in the development of mobile applications for diagnosis and disease management [13]. However, due to the many (fast) developments in eHealth, it is largely unknown which eHealth tools are available and, more importantly, also effective in the treatment of headache patients. Hence, the aim of this study is to (1) review the digital health tools that have been used in headache studies, and (2) discuss the effectivity and reliability of these tools.

\section{Method}

\section{Search strategy}

Online databases PubMed, Cinahl, and PsycINFO were searched to retrieve research studies concerning digital health tools for headache patients. In addition, hand search was performed screening the references of included articles and previous review paper. The search included English articles that were published between January 1st 2000 and January 1 st 2019 . The following main search terms were used: headache; migraine disorder; tension-type headache; cluster headache; headache disorder; telemedicine; patient portal; mobile applications; electronic diary; smartphone; and selfmonitoring. Complete search strategy for each database is described in Table 1.

\section{Study selection}

In total, the search resulted in 969 studies (see Fig. 1). The complete search was then imported into EndNote to remove duplicates. Studies were included if the digital health tool related to measuring or monitoring (e.g. e-diary), meaning (e.g. information provision), or mediating (e.g. communicate with healthcare professional). Next to that, the explanation of the digital health tool had to be a full-length paragraph dealing with an explanatory description of the digital health tool to depict a complete, clear picture of the tool for this review. Studies regarding secondary headache disorders or interventions by telephone were excluded. Two authors (DG and GS) screened all articles as studies independently based on title and abstract using Covidence and made a selection of articles for full text screening. Full texts were screened independently by all four authors. The authors screened half $(50 \%)$ of the studies while ensuring that any single study was screened by two authors; any pair of authors had $25 \%$ overlap in screened studies. During the complete selection process, discrepancies were discussed and subsequently resolved in planned follow-up team meetings. Articles that involved a review were not included in this study, though their referenced articles were checked for presence in our search results, and hand-selected if absent.

\section{Data extraction}

Data extraction was performed by one of the authors (DG) using IBM SPSS Statistics 23 for tabulating the descriptive data from all articles. The following information categories were used from each study: digital health tool category, author, year, country/countries, tool name, operating system, manufacturer/vendor/developer, description of the tool, study design, participant characteristics in studies (sample size, age, and gender), headache type, and primary outcome.

\section{Results}

A total of 39 studies were selected to be included in the review. The extracted data is shown in Table 2. Included articles were published within a time frame of 15 years (2003-2018). Up to and including 2014, one or two articles per year appeared to be relevant to our scoping purpose and therefore included in this review. Since 2015, the number of studies related to digital health tools for headache patients increased. The period from 2015 to 2018 amounted to a total of 26 studies. In sum, the studies included 94,127 
Table 1 Search strategy

\begin{tabular}{|c|c|c|}
\hline Database & Keywords & Hits \\
\hline Cinahl & 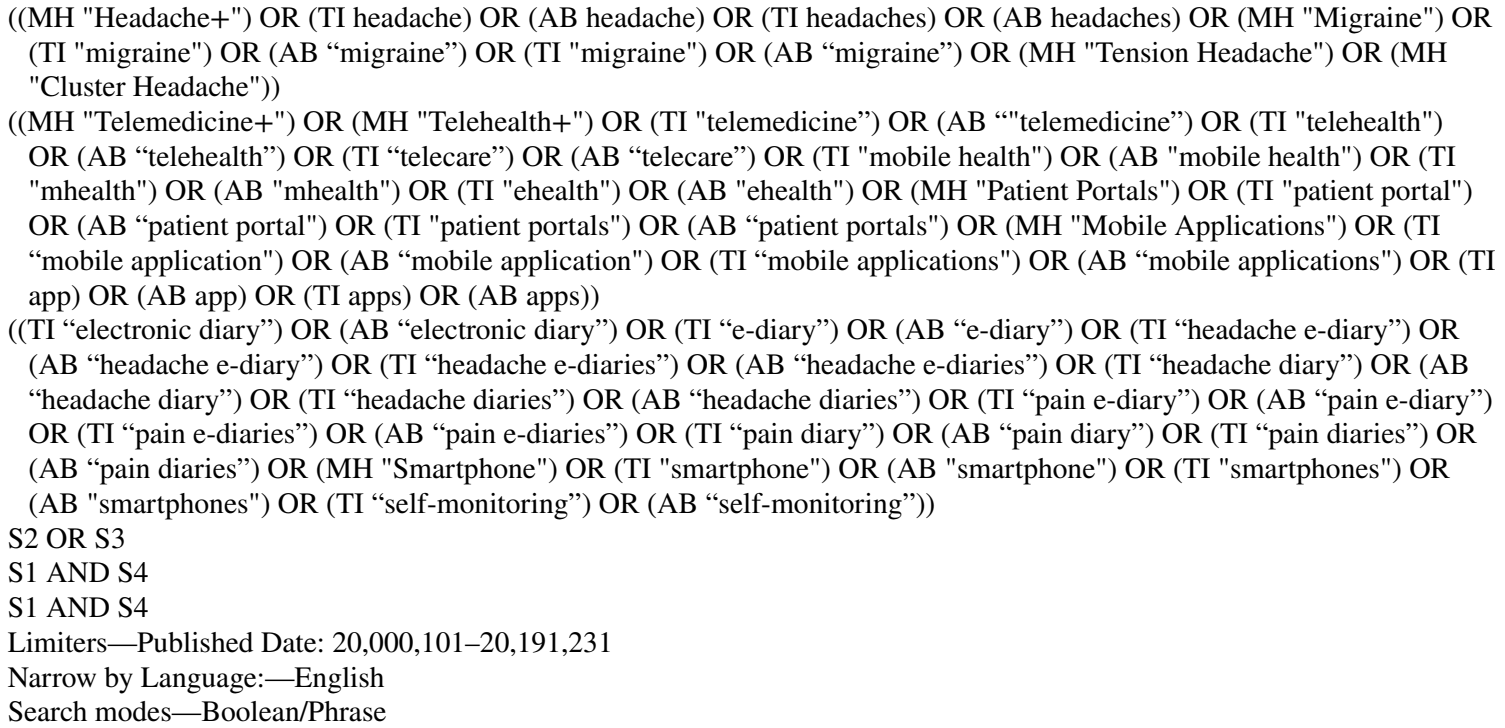 & 273 \\
\hline
\end{tabular}

PsycINFO ((DE "Headache" OR DE "Migraine Headache" OR DE "Muscle Contraction Headache") OR (TI headache) OR (AB headache) OR (TI headaches) OR (AB headaches) OR (MM "Migraine Headache") OR (TI "migraine disorder") OR (AB "migraine disorder") OR (TI "migraine disorders") OR (AB “migraine disorders") OR (MM "Muscle Contraction Headache"))

((MM "Telemedicine") OR (TI "telemedicine") OR (AB “"telemedicine”) OR (TI "telehealth") OR (AB "telehealth") OR (TI "telecare") OR (AB "telecare") OR (TI "mobile health") OR (AB "mobile health") OR (TI "mhealth") OR (AB "mhealth") OR (TI "ehealth") OR (AB "ehealth") OR (TI "patient portal") OR (AB "patient portal") OR (TI "patient portals") OR (AB "patient portals") OR (TI "mobile application") OR (AB "mobile application") OR (TI "mobile applications") OR (AB "mobile applications") OR (TI app) ...

((TI "electronic diary") OR (AB “electronic diary") OR (TI "e-diary”) OR (AB “e-diary”) OR (TI "headache e-diary”) OR (AB "headache e-diary") OR (TI "headache e-diaries") OR (AB "headache e-diaries") OR (TI "headache diary") OR (AB "headache diary") OR (TI "headache diaries") OR (AB "headache diaries") OR (TI "pain e-diary") OR (AB "pain e-diary") OR (TI "pain e-diaries") OR (AB "pain e-diaries") OR (TI "pain diary") OR (AB "pain diary") OR (TI "pain diaries") OR (AB "pain diaries") OR (MM "Cell ...

S2 OR S3

S1 AND S4

Limiters-Publication Year: 2000-2019

Expanders-Apply equivalent subjects

Narrow by Language:- - english

Search modes-Boolean/Phrase

PubMed (("headache"[MeSH Terms] OR headache[Title/Abstract] OR headaches[Title/Abstract]) OR ("migraine disorders"[MeSH Terms] OR "migraine disorder"[Title/Abstract] OR "migraine disorders"[Title/Abstract]) OR ("tension-type headache"[MeSH Terms] OR "tension-type headache"[Title/Abstract] OR "tension-type headaches"[Title/Abstract] OR "tension type headache"[Title/Abstract] OR "tension type headaches"[Title/Abstract]) OR ("cluster headache"[MeSH Terms] OR "cluster headache"[Title/Abstract] OR "cluster headaches"[Title/Abstract]) OR ("headache disorders"[MeSH Terms] OR "headache disorder"[Title/Abstract] OR "headache disorders"[Title/Abstract])) AND (("telemedicine"[MeSH Terms] OR "telemedicine"[Title/Abstract] OR "telehealth"[Title/Abstract] OR "telecare"[Title/Abstract] OR "mobile health"[Title/Abstract] OR "mhealth"[Title/Abstract] OR "ehealth"[Title/Abstract]) OR ("patient portals"[MeSH Terms] OR "patient portal"[Title/Abstract] OR "patient portals"[Title/Abstract]) OR ("mobile applications"[MeSH Terms] OR "mobile application"[Title/Abstract] OR "mobile applications"[Title/Abstract] OR app[Title/Abstract] OR apps[Title/Abstract]) OR ("electronic diary"[Title/Abstract] OR "e-diary"[Title/Abstract] OR "headache e-diaries"[Title/Abstract] OR "headache diary"[Title/Abstract] OR "headache diaries"[Title/Abstract] OR "pain diary"[Title/Abstract] OR "pain diaries"[Title/ Abstract]) OR ("smartphone"[MeSH Terms] OR "smartphone"[Title/Abstract] OR "smartphones"[Title/Abstract]) OR "selfmonitoring"[Title/Abstract])) AND (("2000/01/01"[PDAT]: "3000/12/31"[PDAT]) AND (Dutch[lang] OR English[lang]))

participants. One study did not report the number of participants. The majority of studies mainly had female participants. In four studies, males were not included at all. For
20 studies, participants were adults only. Four studies only included children and eight studies included both children and adults. Studies mainly focused on migraine $(N=29$ out 
Fig. 1 Flow diagram

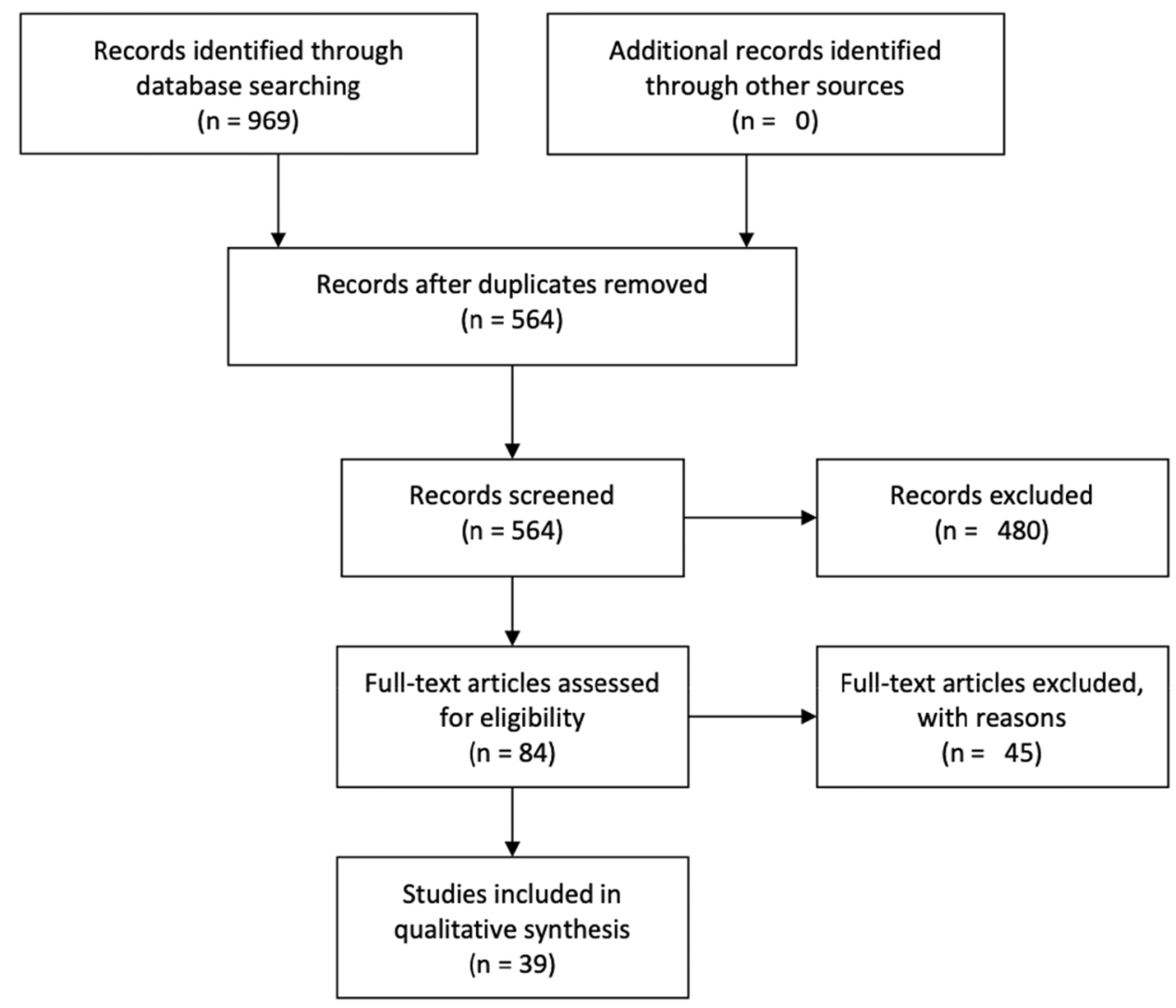

of 39), cluster headache ( $N=14$ out of 39$)$, and tensiontype headache ( $N=8$ out of 39 ), concurrently or independently. Other types of headache were examined by 25 studies, including medication-overuse headache and non-acute headache. The included studies in the search mainly entailed observational prospective cohort studies $(N=15$ out of 39$)$ and parallel-group randomized controlled trials $(N=12$ out of 39). A summative usability evaluation was reported in four studies and an observational retrospective cohort study was included in three studies. Two articles included a formative usability evaluation (pilot) study. Qualitative formative usability study, single case clinical (or AB - Baseline-Intervention) study, and (web) development of an electronic diary were all conducted only once.

\section{Digital health tool characteristics}

All studies were classified among different digital health tool categories (see Table 2). The majority of studies focused on diaries ( $N=27$ out of 39$)$. These diaries are being used to gather insight in symptom frequency and severity, keep track of medication use and provide a disease burden overview to the care provider. Digital (cognitive) behavioral therapy were also quite common ( $N=7$ out of 39$)$. Other digital health tool categories were tele-consultations $(N=4$ out of 39), telemonitoring (medication adherence) $(N=2$ out of 39) and patient portal (patient-doctor) ( $N=2$ out of 39). One study examined a headache training tool for specialists. Tool names were not mentioned in 16 studies. In 17 studies, the operating platform was not mentioned. iOS was the main operating system as a platform that was most often used ( $N=8$ out of 39). Android and Windows CE were both mentioned in three articles as operating system. Other operating platforms were among others a Cisco proprietary platform, a Web-based platform (HTML), and a Java-based platform. Platform use is timeline specific. Internet platform technologies continue to change from years to years.

\section{Potential patient benefits of digital health tools for headache}

Current search revealed that one of the most prominent eHealth tools used by patients with headache is an electronic headache diary. According to the evaluated studies, using an electronic headache diary seems to contribute to a more clear diagnosis, better assessment of headache burden, and accurate medication use and therapy response. Besides being a device for measurement, the use of electronic diaries also showed benefits in reducing medication overuse and improving medication adherence, identification of triggers or premonitory symptoms, the timing of headache attacks, the perceived pain during headache attacks, the main headache 


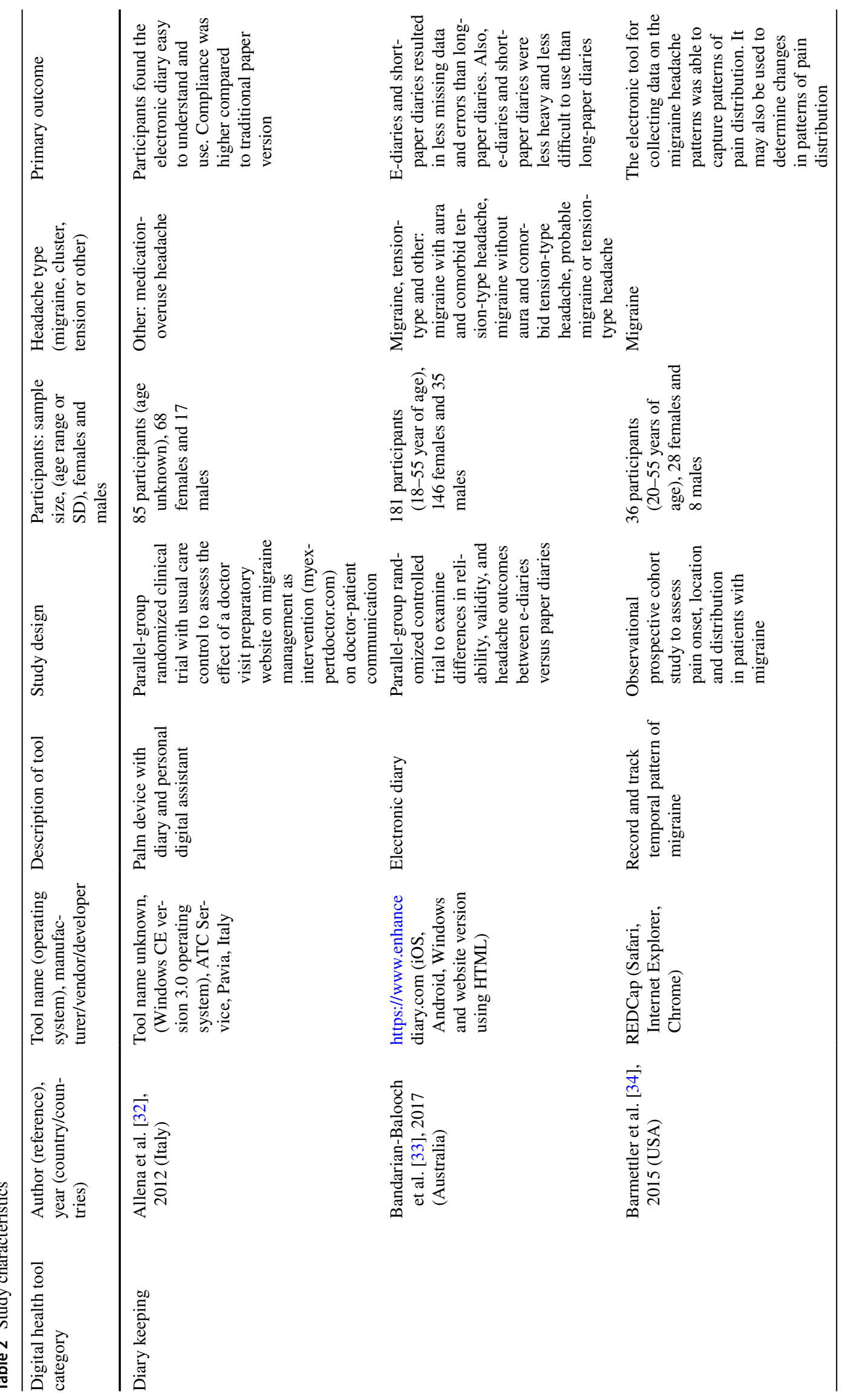




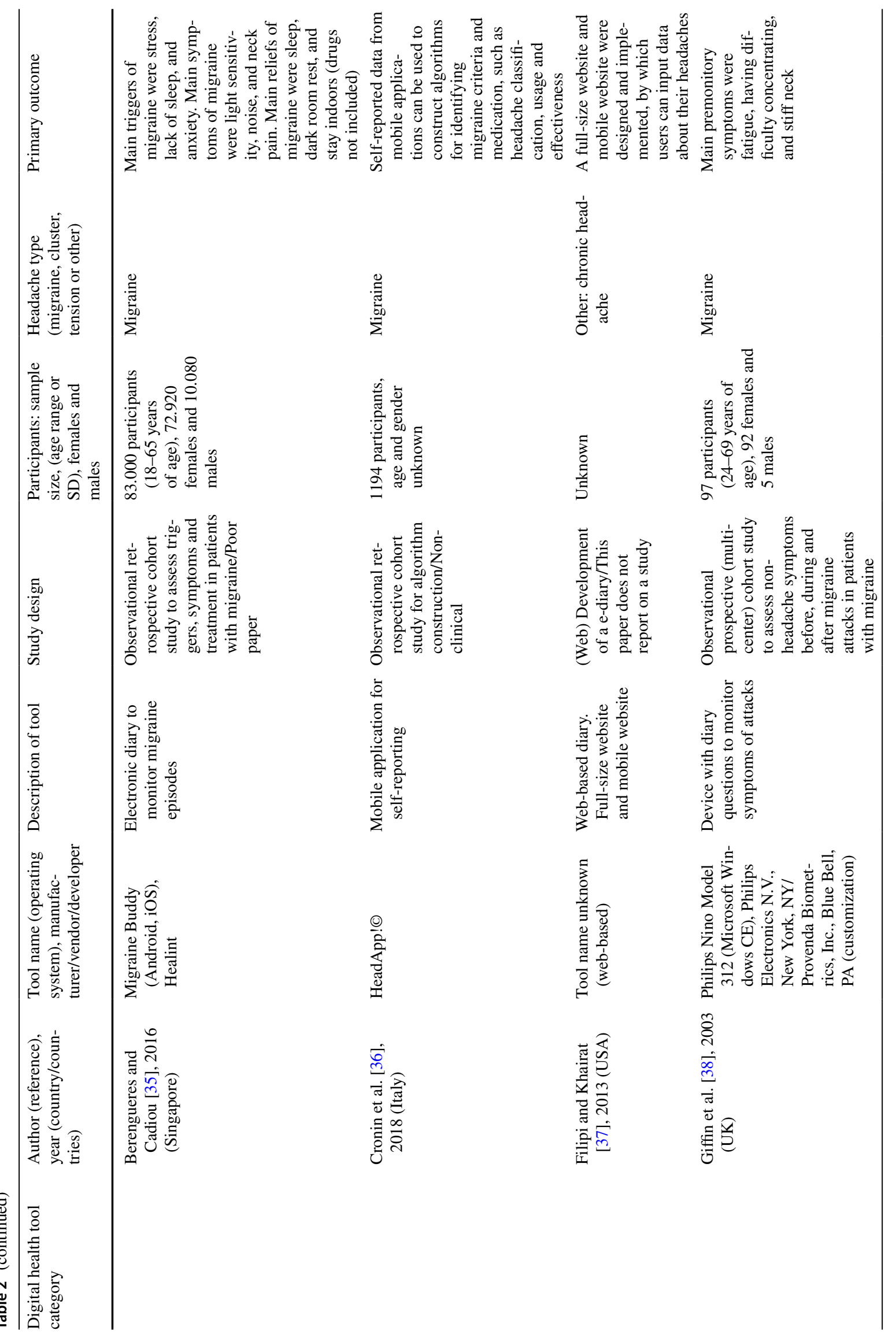




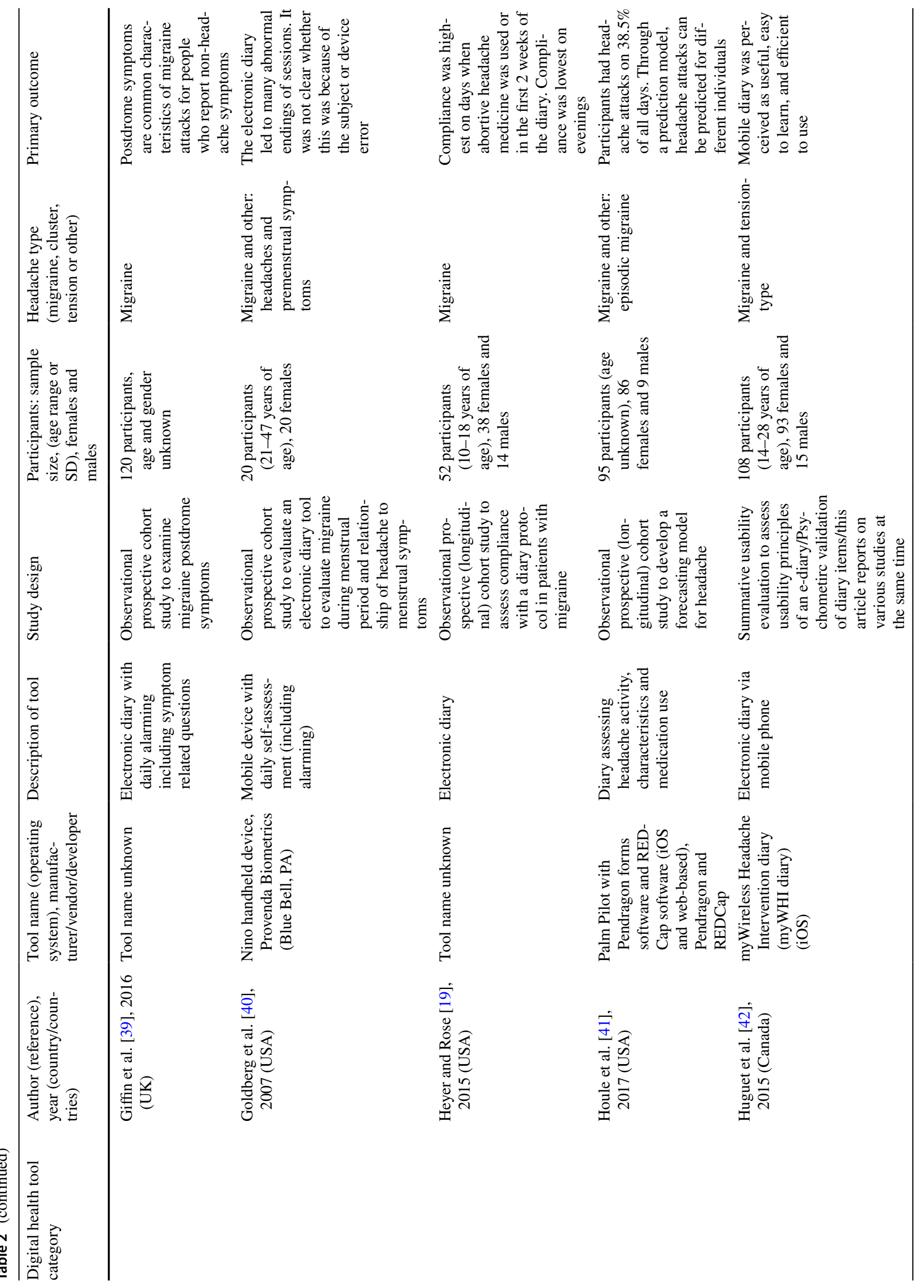




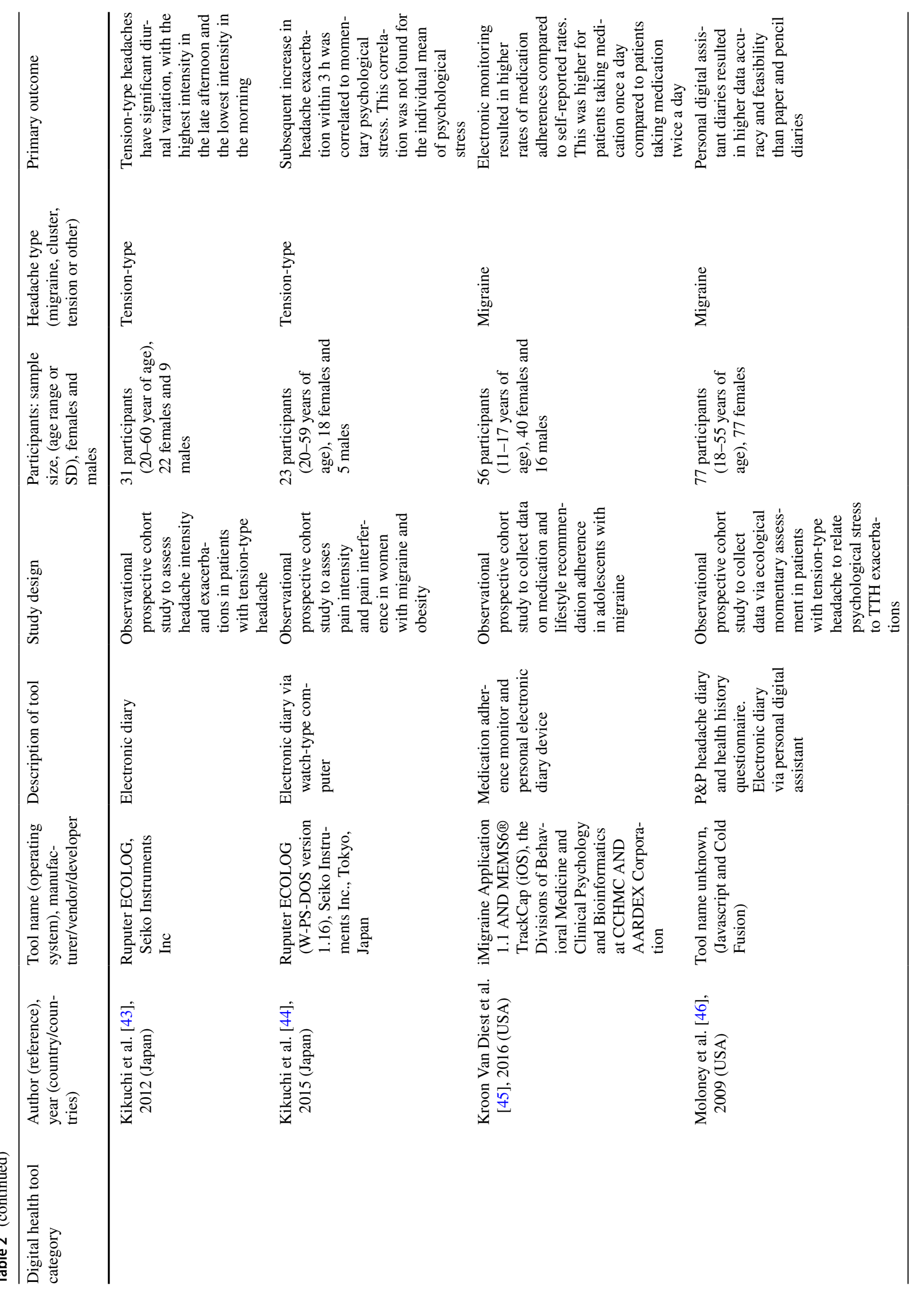




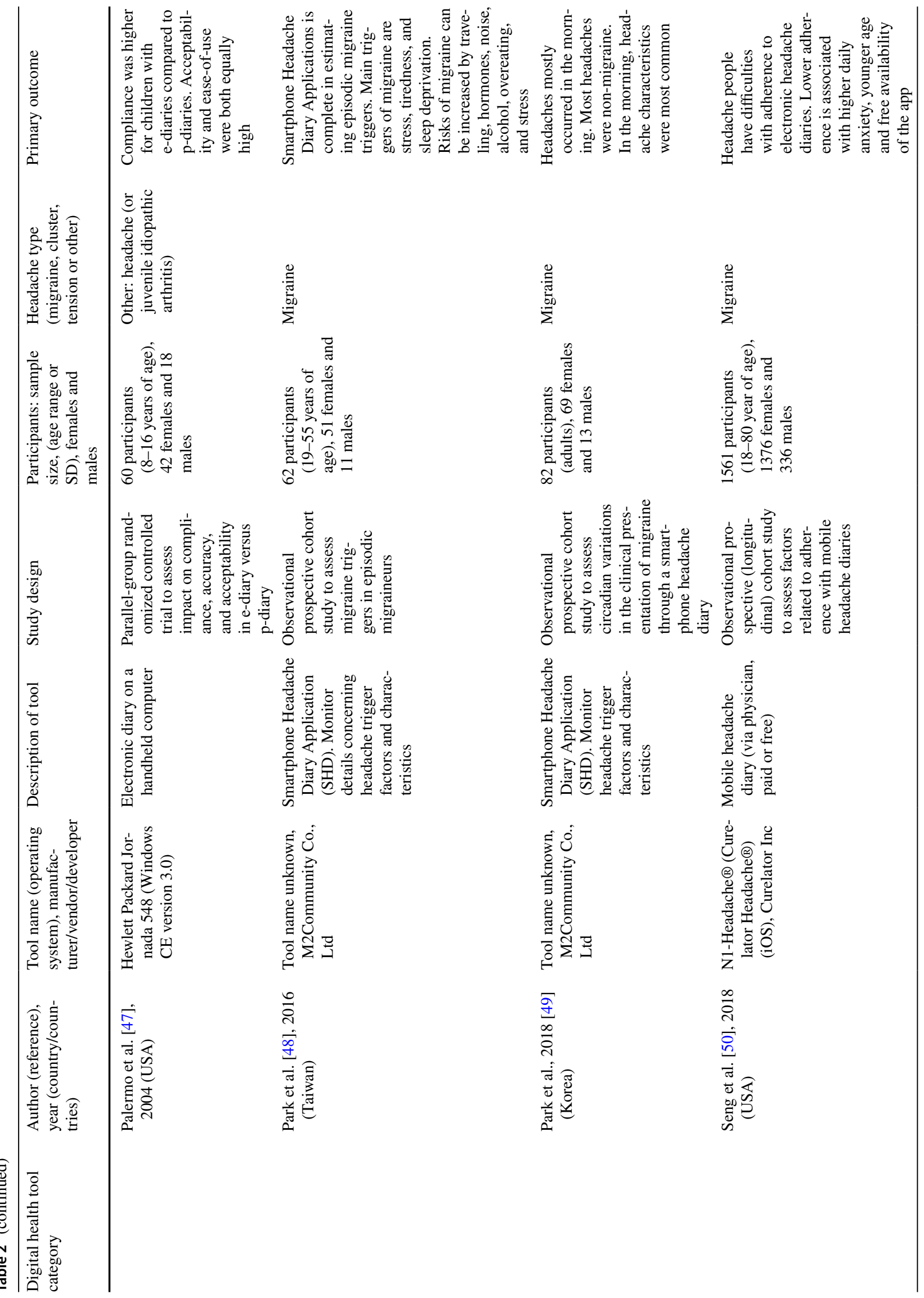




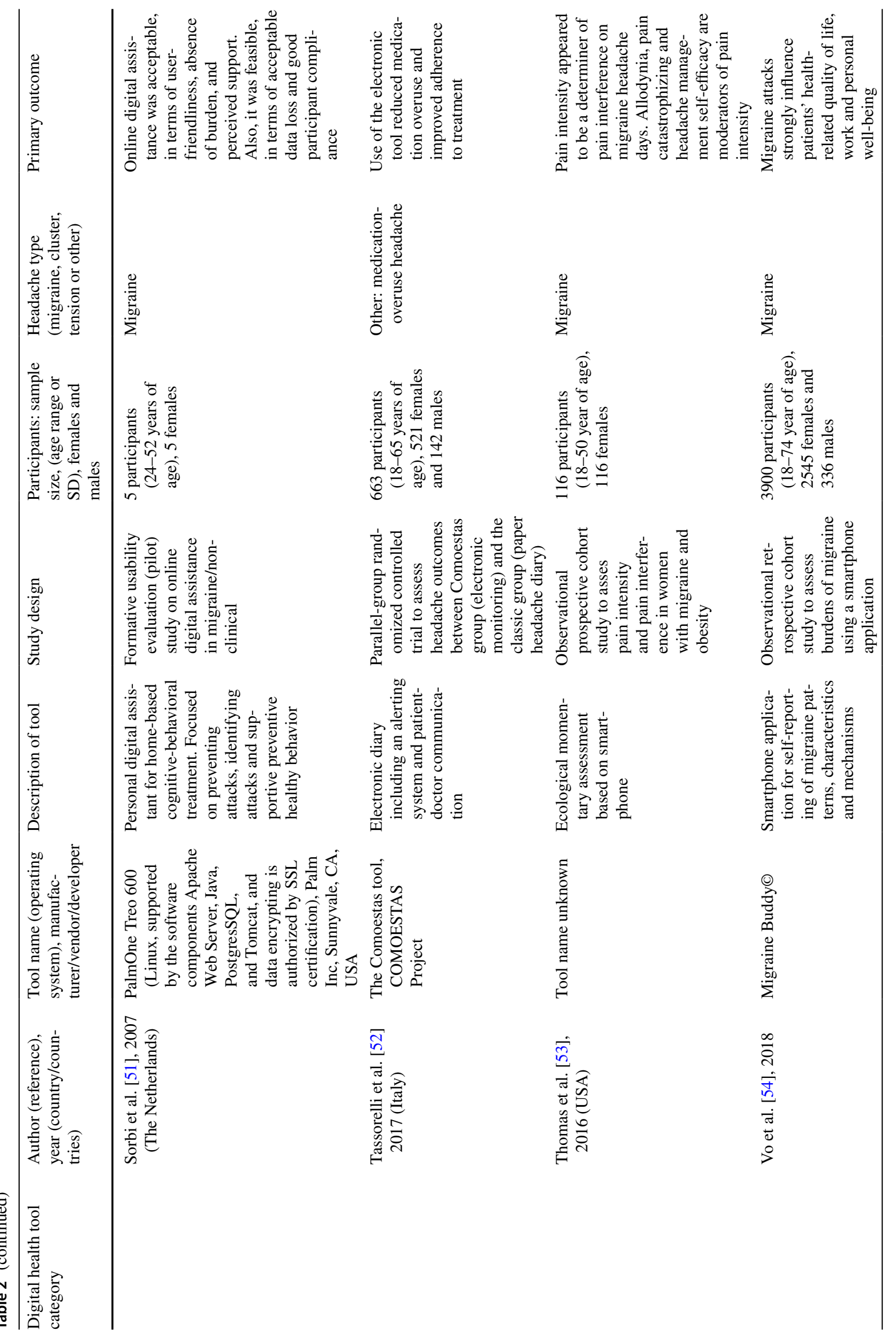




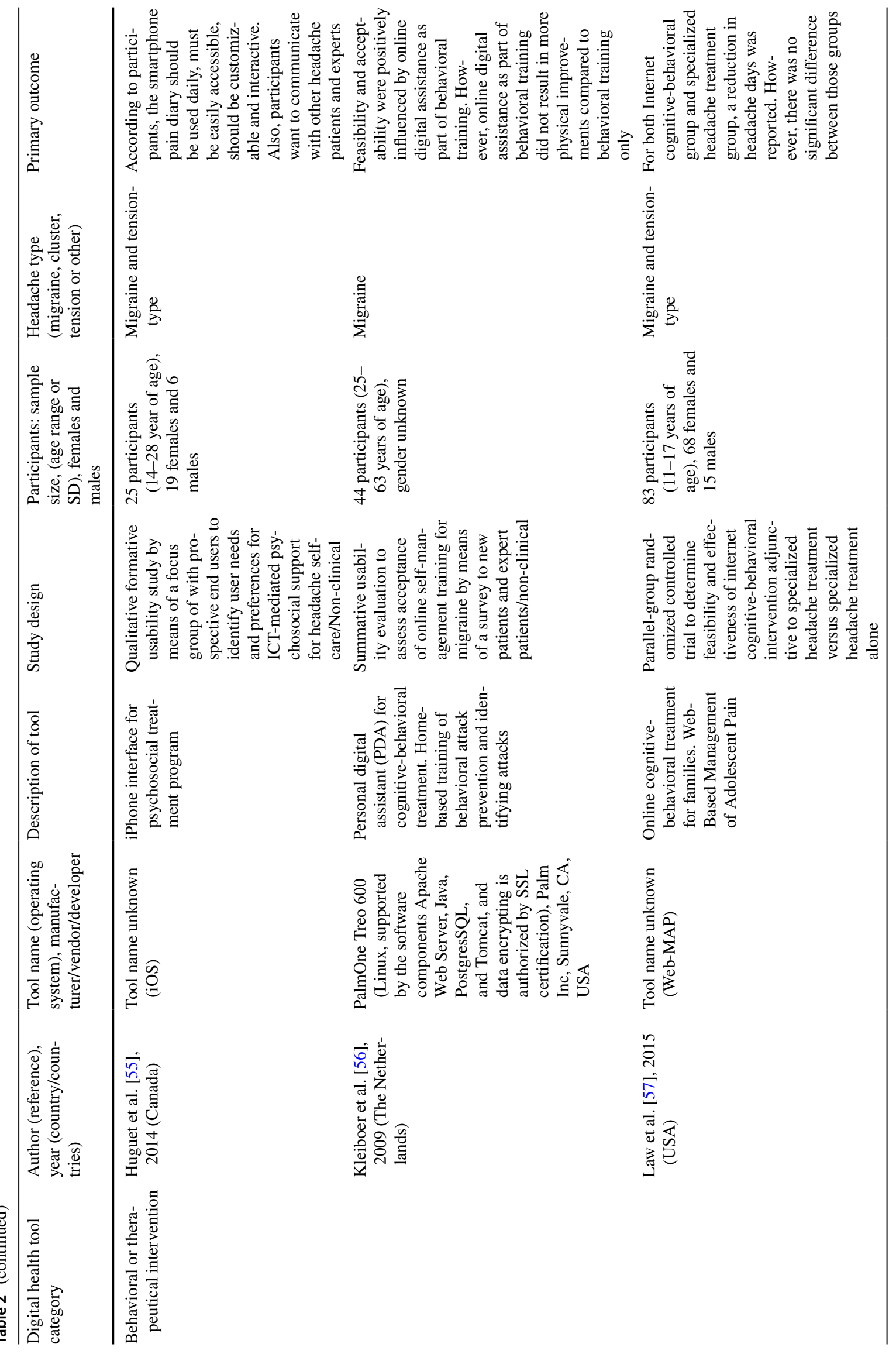




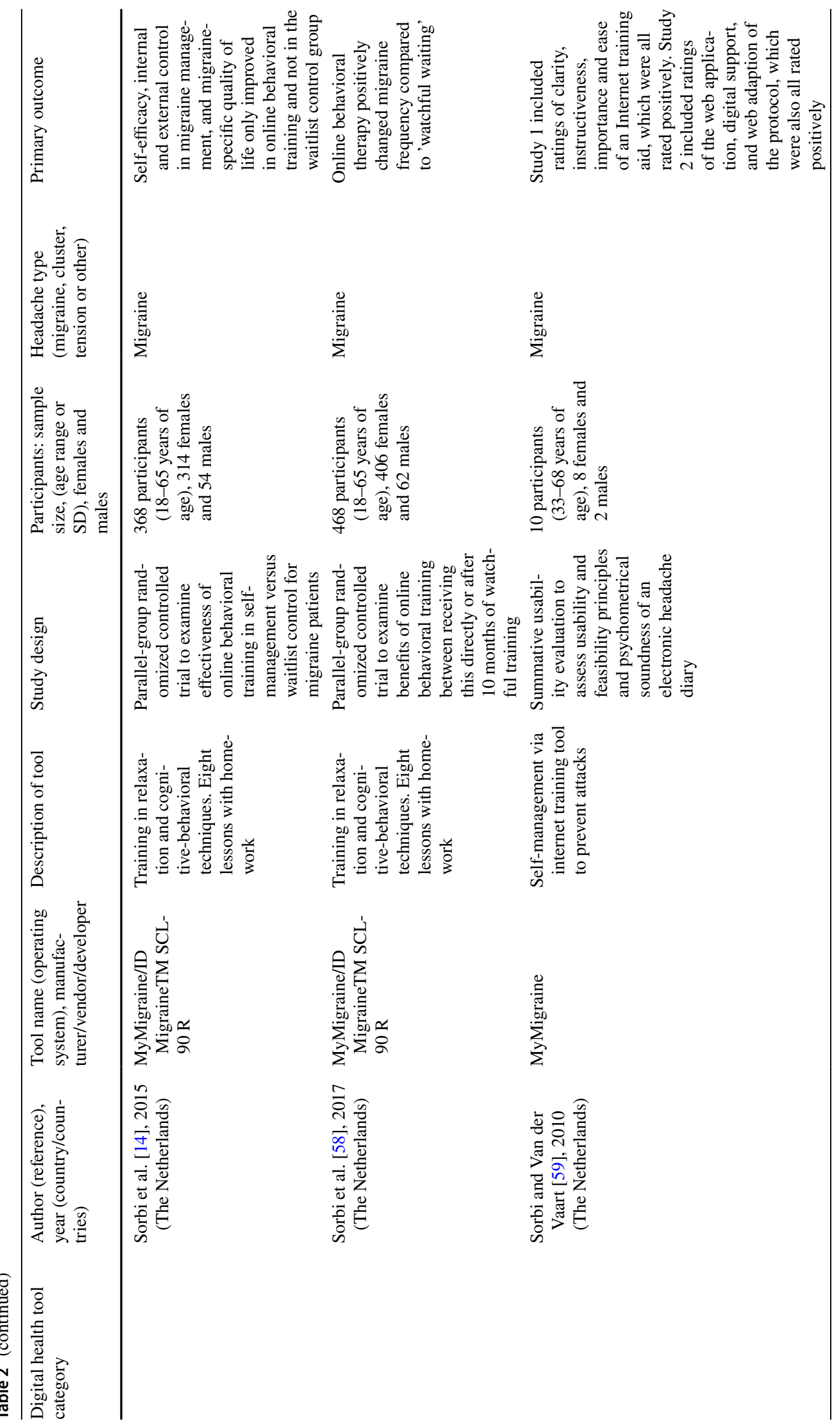




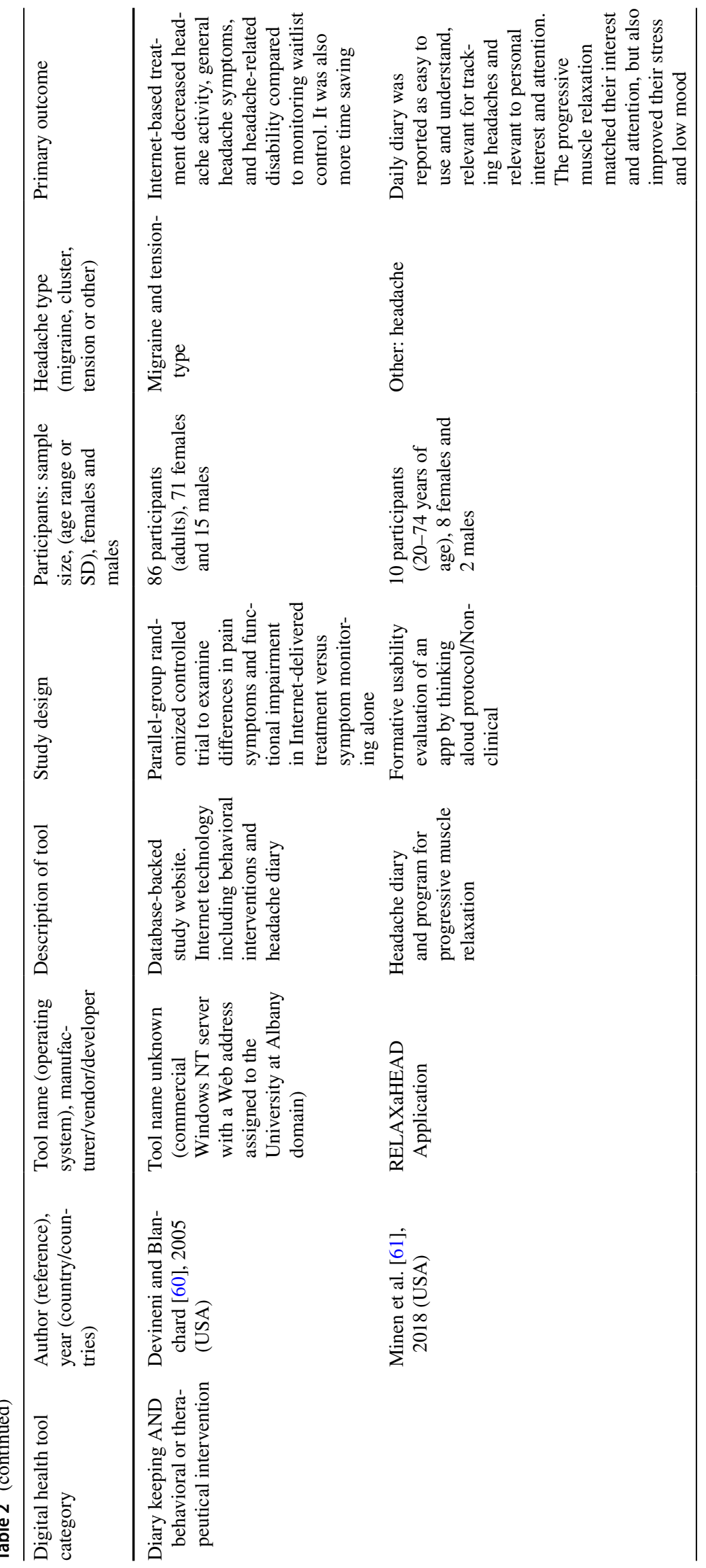




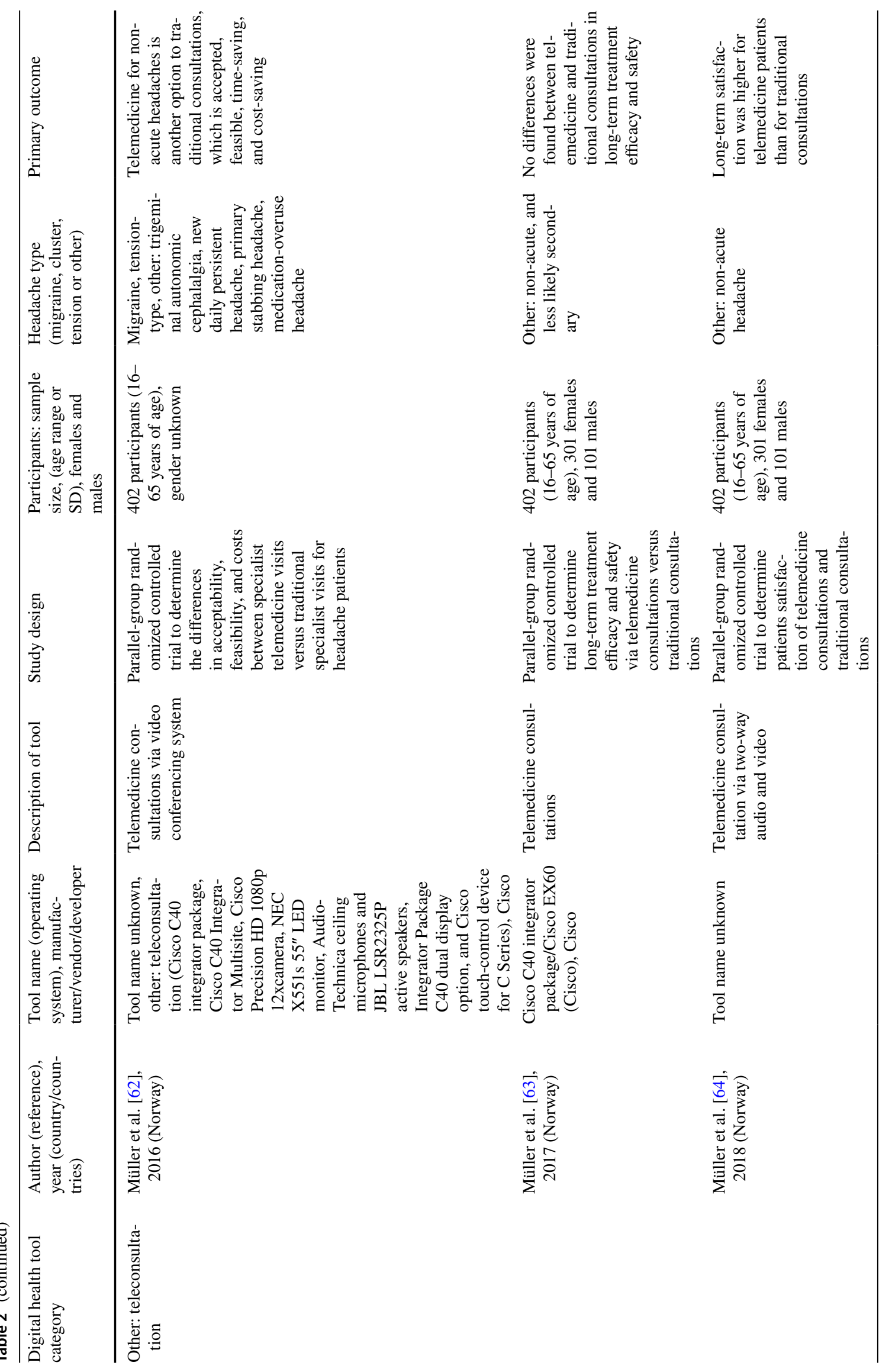




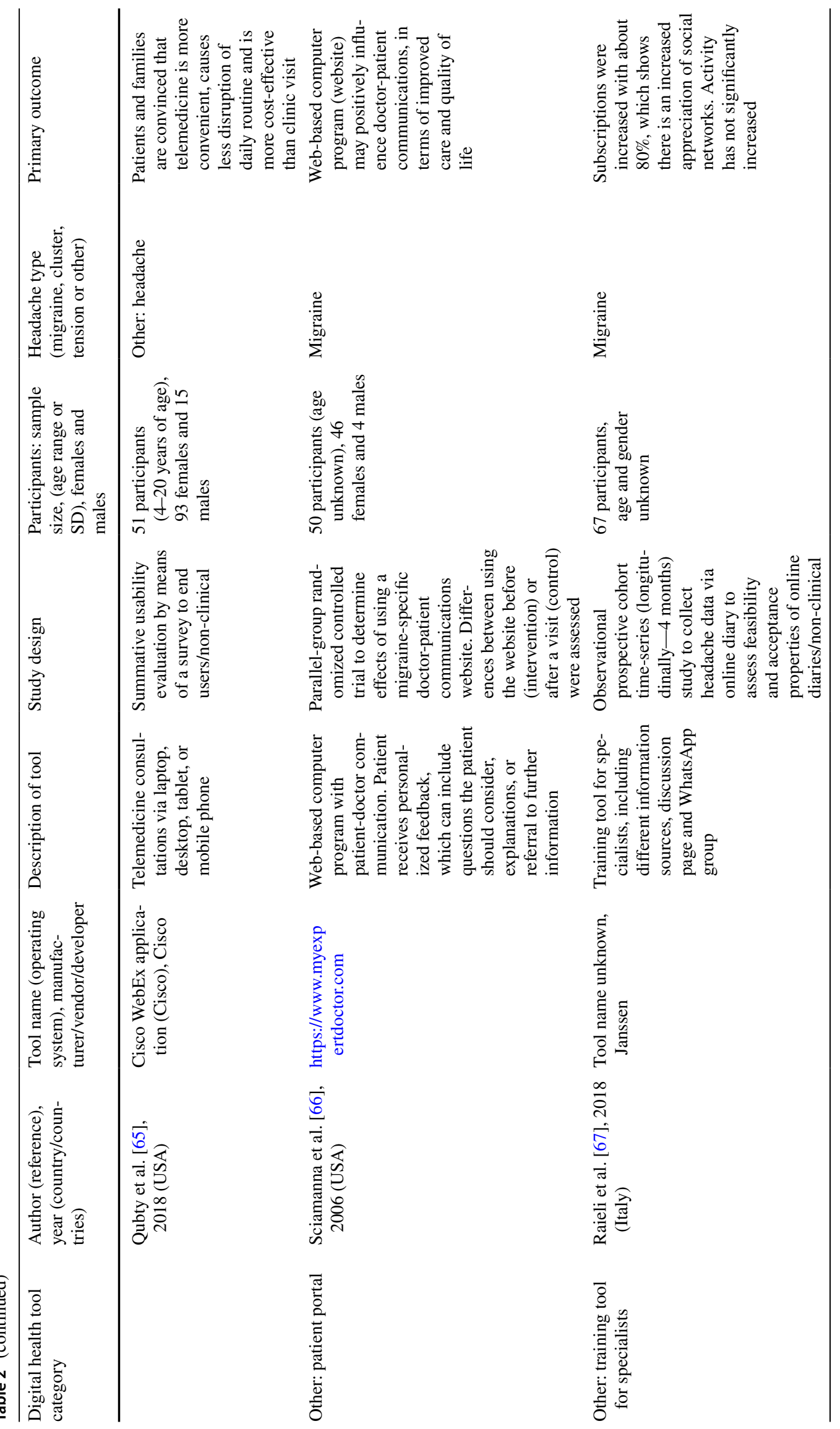




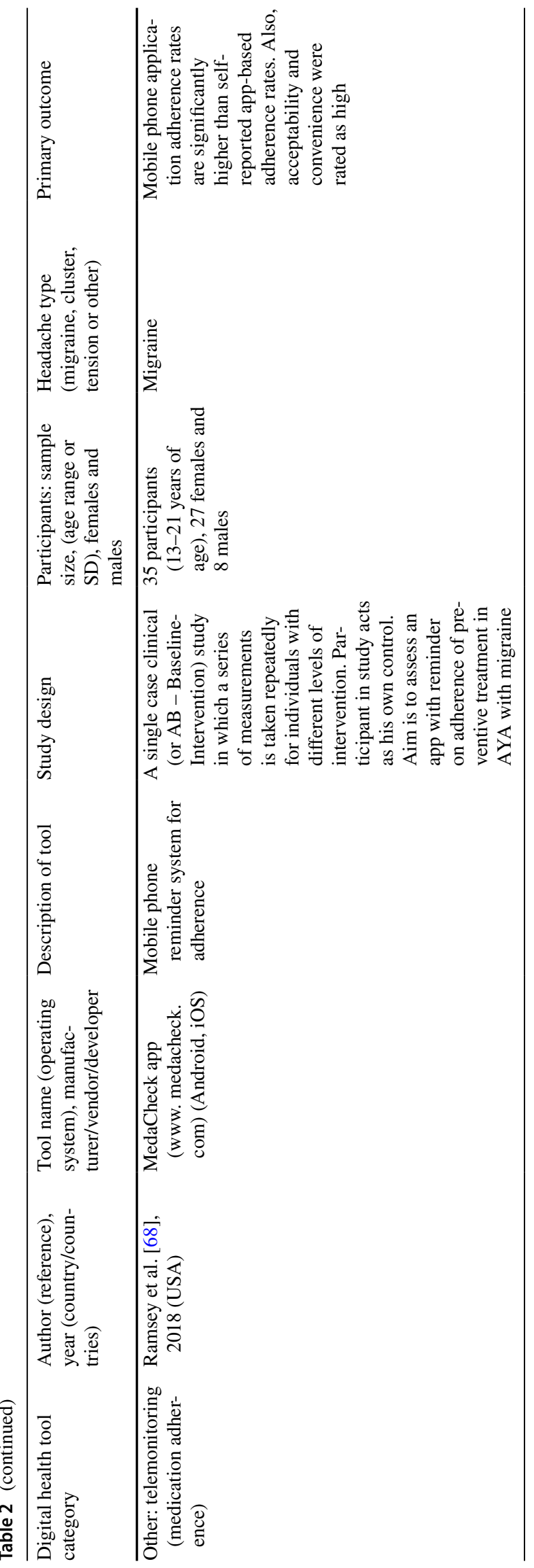

reliefs, and the impact of headache attacks on perceived quality of life (Table 2).

Besides headache diaries, a significant number of studies ( $N=7$ out of 39 ) has reported the results of online behavioral interventions aiming to reduce the headache burden. Relaxation training and cognitive-behavioral therapy have been evaluated as behavioral modalities and showed limited benefit. The use of an online relaxation or cognitivebehavioral training program showed a reduction in headache attack frequency or symptoms in comparison to "watchful monitoring' alone, while its benefit as an adjunctive digital therapy to a specialized headache treatment is still not demonstrated. In addition, in their study, Sorbi et al. [14] showed that self-efficacy, control of migraine management, and migraine related quality of life increased in the intervention group as compared to the waiting list controls (Table 2).

Tele-consultation is the third major area of digital tools used in headache therapy. Tele-consultations are seen as non-inferior (or equivalent) to traditional consultations in safety and efficacy, but are thought to be more convenient and more cost-effective by patients and can positively influence patient-doctor communication (Table 2).

\section{Discussion}

This scoping review aimed to survey available digital health tools for headache patients that can be used to gather insights into the disease, measure symptoms' severity, and facilitate communication with health professionals. Our search revealed that most studies investigated headache diaries $(N=27)$ or online (cognitive) behavioral therapy $(N=7)$. Only a few studies looked at tele-consultations, patient portals, and telemonitoring including medication adherence. Based on the findings from these studies it can be concluded that electronic headache diaries are a must-have in the treatment delivery to patients with headache, both as an essential self-reported outcome measurement device. Only via daily self-reports, treatment options can detail out true patient benefits in timed events, location, signs and symptoms. Additionally, sincere self-report on lifestyle can help in identifying behaviors that might act as a cause or precursor in prodromal headache exacerbation stages like medication overuse and stress. However, diary adherence is a problem; diaries need to be improved in learnability and ease-of-use. Electronic diaries, as part of digital therapeutics proposition to patients, require multi-center clinical studies with patient cohorts to assess the effectiveness and truth worthiness of what will be self-reported. Online cognitive-behavioral therapy (CBT) is the foremost example of a digital therapeutics solution that could be applied to patients with headache complaints [10]. However, clinical supervision and 
professional improvement will further extend the potential relief and health benefits to patients.

The current review identified 27 different studies. In a review from 2014 a total of 38 different headache apps were identified [13] and at the time of writing this review the authors identified more than 100 headache apps in the Google play store only. According to a recent study [15], there are more than 120,000 mobile medical apps available in the various App Stores and across mobile platforms. Headache app can support the health journey of headache patients in several ways like providing digital headache education, diary keeping, classifying headache attacks, and keeping track of medication adherence. Some apps have more advanced features for measuring daily occurrence of a long list of trigger factors in combination with headache symptoms providing a detailed report on potential personal triggering mechanisms [16]. Data collected by means of diaries can be used in predicting the occurrence of headache attacks allowing for pro-active self-management [17, 18]. However, a large portion of people with headache finds difficulties in adhering to keeping a diary [19, 20]. Higher level of daily anxiety, younger age and free availability of the diary tool are associated with poorer adherence [20]. Apps can also be used to capture medical information in randomized clinical trials; they are then used as a measuring instrument to support the purpose of the trial [21]. We observed that many apps (>80\%) have been created without early or long-standing involvement of patients, medical professionals or representatives of the scientific community [13]. A recent review on medication apps showed that $15 \%$ of apps is produced as a co-creation effort with health care providers and $2.1 \%$ in collaboration with academia [22]. If health apps are considered medical devices dependent on their intended medical purpose of use, they need to be assessed or even certified on their usability, usefulness, patient safety, credibility and health effect, similar to pharmaceutical therapies [23]. It is therefore reassuring that the EU has formed national working groups to align and prepare for EU guidelines on 'good and safe' health apps. In addition, trustworthy institutions such as the National Health Service provide online facilities to recommend well-functioning health apps. Headache apps should be scrutinized on their safety and usability properties as well.

The second category of eHealth tools that we identified focuses on digital (cognitive) behavioral therapy. Studies showed that behavioral treatment is acceptable and feasible [24] in this population. However, the number of randomized controlled trials evaluating the effectiveness of behavioral interventions for patients with headache is relatively small and show mixed findings. This advocates for future studies to focus on development and evaluation of these interventions as previous studies in other patient samples have shown very promising results [25]. For patients suffering from headache online behavioral treatment could focus on specific triggers that have been associated with headache (e.g. distress, lifestyle, medication adherence). Previous studies have shown that online behavioral treatment can be as effective as faceto-face treatment in reducing distress $[9,10]$. In addition, it might be a cost-effective way tor reach large proportions of the targeted population [26]. However, studies do show that online treatment is more likely to be effective when blended with personal contact between patient and therapist [27]. A fully automated treatment is less likely to be effective as 'one size fits all' approach seems not to be the way forward [28]. Hence, future studies should focus on, blended care, personalized interventions that appeal to patients' needs and preferences, but are at the same time scalable.

The third category includes a few studies on patient portals, tele-consultations and telemonitoring including medication adherence. Patient portals enable patient to look at their charts and imaging results, but also to make future appointments and communicate with their doctor. In countries where electronic health records are installed, the use of such portals is rapidly increasing [29]. Empowering patients with their own health data can cause some anxiety, but it also improves health education and awareness [30]. Teleconsultations and monitoring are more advance digital technique to replace current out-patient clinic visits. In situations where patients have to travel $2 \mathrm{~h}$ to talk $15 \mathrm{~min}$ to their doctor a video consult is often preferred. Even for new patient contacts, the use of video consultation seems feasible [31].

The current review has some limitations. First, we were only able to include English studies from three databases and may have missed important studies that were not published in the included journals. Second, only practical and logistic properties of the tools were described. Clinometric properties (effectiveness and safety) were not formally studied. It was not possible to perform a meta-analysis due to the limited number of randomized controlled trials and the heterogeneity of their designs and purpose. Third, there are application domains in headache therapy that have not been fully implemented or researched and are therefore underrepresented or even missing in this review. Hence, we would encourage more research and implementation effort in understanding patient use of online information resources for their headache complaints, symptom checkers, digital peer support, remote tele monitoring, the collection and analysis of patient reported outcome metrics (PROMs) in therapy and the use of wearables in collecting data on disease burden and lifestyle.

Future research regarding other digital health tool categories than dairies and behavioral/therapeutical treatment is needed, namely tele-consultations, patient portals, telemonitoring including medication adherence, online information resources, symptom checkers, digital peer support, telemonitoring including proms and telemonitoring including 
wearables. This will fill the gap in literature regarding digital health tools for headache patients. Next to that, effectiveness of all types of digital health tool categories should be examined. This was not included in most studies, while it seems to be an important aspect because ineffective tools can lead to discrepant and misleading claims, and insufficient quality of the tools [32]. We recommend that health professionals in the headache field, such as general practitioners and neurologists, get inspired by scientific research about digital health tools in other fields than headache. These tools may have a different focus, but the processes and goals behind these tools will be comparable to headache tools.

In summary, many digital health tools for headache patients regarding diaries and behavioral/therapeutical treatment are described in scientific research. However, much scientific knowledge with regard to other categories is still missing. To be more able to ensure quality of digital health tools for headache patients, more knowledge is needed. This mainly relates to tele-consultations, patient portals, telemonitoring including medication adherence, online information resources, symptom checkers, digital peer support, telemonitoring including proms, and telemonitoring including wearables. Without doubt, electronic headache diaries are key to help clarifying diagnosis, headache burden, medication use and therapy response. However, patients are struggling to keep their diaries in a continued and systematic way. Simplification of headache diaries needs to lower data entry burden for patients helping to improve diary compliance.

\section{Key findings}

- Earlier scientific research regarding eHealth for headache patients mainly described electronic diaries and behavioral or therapeutical treatments. Future eHealth studies should focus on the benefits and clinometric properties of these tools. Outcome measures preferably include validated headache and migraine outcome parameters to increase generalizability across studies.

- More knowledge about tele-consultations, patient portals, telemonitoring including medication adherence, online information resources, symptom checkers, digital peer support, telemonitoring including proms, and telemonitoring including wearables is needed.

\section{Availability of data and material}

The data that support the findings of this study are available on request from the corresponding author.

Author contributions All authors contributed to the study conception, design, material preparation, data collection and analysis. The first draft of the manuscript was written by D.L. van de Graaf and all authors commented on previous versions of the manuscript. All authors read and approved the final manuscript.

Funding This review project had no external funding source.

\section{Compliance with ethical standards}

Conflicts of interest The authors declare that they have no conflict of interest.

Open Access This article is licensed under a Creative Commons Attribution 4.0 International License, which permits use, sharing, adaptation, distribution and reproduction in any medium or format, as long as you give appropriate credit to the original author(s) and the source, provide a link to the Creative Commons licence, and indicate if changes were made. The images or other third party material in this article are included in the article's Creative Commons licence, unless indicated otherwise in a credit line to the material. If material is not included in the article's Creative Commons licence and your intended use is not permitted by statutory regulation or exceeds the permitted use, you will need to obtain permission directly from the copyright holder. To view a copy of this licence, visit http://creativecommons.org/licenses/by/4.0/.

\section{References}

1. Wiendels NJ, Knuistingh Neven A, Rosendaal FR, Spinhoven P, Zitman FG, Assendelft WJ et al (2006) Chronic frequent headache in the general population: prevalence and associated factors. Cephalalgia 26(12):1434-1442

2. Davies PTG, Lane RJM, Astbury T, Fontebasso M, Murphy J, Matharu M (2019) The long and winding road: the journey taken by headache sufferers in search of help. Prim Health Care Res Dev 20:e4

3. Leonardi M, De La Torre ER, Steiner TJ, Tinelli M, Raggi A, D'Amico D et al (2018) Value of treatment of headache patients and need to improve headache patients' journey. Neurol Sci 39(Suppl 1):115-116

4. Palacios-Ceña D, Neira-Martín B, Silva-Hernández L, MayoCanalejo D, Florencio LL, Fernández-de-Las-Peñas $C$ et al (2017) Living with chronic migraine: a qualitative study on female patients' perspectives from a specialised headache clinic in Spain. BMJ Open 7(8):e017851

5. Mosadeghi-Nik M, Askari MS, Fatehi F (2016) Mobile health (mHealth) for headache disorders: a review of the evidence base. J Telemed Telecare 22(8):472-477

6. Stubberud A, Linde M (2018) Digital technology and mobile health in behavioral migraine therapy: a narrative review. Curr Pain Headache Pain 22(10):66

7. Makin S (2019) The emerging world of digital therapeutics. Nature 573(7775):S106-S109

8. Müller KI, Alstadhaug KB, Bekkelund SI (2017) Headache patients' satisfaction with telemedicine: a 12-month follow-up randomized non-inferiority trial. Eur J Neurol 24(6):807-815

9. Andrews G, Cuijpers P, Craske MG, McEvoy P, Titov N (2010) Computer therapy for the anxiety and depressive disorders is effective, acceptable and practical health care: a meta-analysis. PLoS ONE 5(10):e13196

10. Cuijpers P, van Straten A, Andersson G (2008) Internet-administered cognitive behavior therapy for health problems: a systematic review. J Behav Med 31(2):169-177 
11. Lotman EM, Viigimaa M (2020) Digital health in cardiology: the Estonian perspective. Cardiology 145(1):21-26

12. Inglis SC, Clark RA, McAlister FA, Stewart S, Cleland JGF (2011) Which components of heart failure programmes are effective? A systematic review and metaanalysis of the outcomes of structured telephone support or telemonitoring as the primary component of chronic heart failure management in 8323 patients: Abridged Cochrane Review. Eur J Heart Fail 13:1028-1040

13. Hundert AS, Huguet A, McGrath PJ, Stinson JN, Wheaton M (2014) Commercially available mobile phone headache diary apps: a systematic review. JMIR Mhealth Uhealth 2(3):e36

14. Sorbi MJ, Kleiboer AM, van Silfhout HG, Vink G, Passchier J (2015) Medium-term effectiveness of online behavioral training in migraine self-management: a randomized trial controlled over 10 months. Cephalalgia 35(7):608-618

15. Carroll JK, Moorhead A, Bond R, LeBlanc WG, Petrella RJ, Fiscella K (2017) Who uses mobile phone health apps and does use matter? A secondary data analytics approach. J Med Internet Res 19(4): 125

16. Peris F, Donoghue S, Torres F, Mian A, Wöber C (2017) Towards improved migraine management: determining potential trigger factors in individual patients. Cephalalgia 37(5):452-463

17. Houle TT, Turner DP, Golding AN, Porter JAH, Martin VT, Penzien DB et al (2017) Forecasting individual headache attacks using perceived stress: development of a multivariable prediction model for persons with episodic migraine. Headache 57(7):1041-1050

18. Cronin AH, Sterzi R, Perteghella D, Agostoni EC, Frediani F (2018) Can the app HeadApp!(c) be useful in migraine epidemiology? A proposal of a digital algorithm for migraine criteria. Neurol Sci 39(Suppl 1):141-142

19. Heyer GL, Rose SC (2015) Which factors affect daily compliance with an internet headache diary among youth with migraine? Clin J Pain 31(12):1075-1079

20. Seng EK, Prieto P, Boucher G, Vives-Mestres M (2018) Anxiety, incentives, and adherence to self-monitoring on a mobile health platform: a naturalistic longitudinal cohort study in people with headache. Headache 58(10):1541-1555

21. Schmitz H, Howe CL, Armstrong DG, Subbian V (2018) Leveraging mobile health applications for biomedical research and citizen science: a scoping review. J Am Med Inform Assoc 25(12):1685-1695

22. Tabi K, Randhawa AS, Choi F, Mithani Z, Albers F, Schnieder M et al (2019) Mobile apps for medication management: review and analysis. JMIR Mhealth Uhealth 7(9):e13608

23. Wattanapisit A, Teo CH, Wattanapisit S, Teoh E, Woo WJ, Ng CJ (2020) Can mobile health apps replace GPs? A scoping review of comparisons between mobile apps and GP tasks. BMC Med Inform Decis Mak 20(1):5

24. Kleiboer A, Sorbi M, Merelle S, Passchier J, van Doornen L (2009) Utility and preliminary effects of online digital assistance (ODA) for behavioral attack prevention in migraine. Telemed J E Health 15(7):682-690

25. Van Vugt VA, van der Wouden JC, Essery R, Yardley L, Twisk JWR, van der Horst HE et al (2019) Internet based vestibular rehabilitation with and without physiotherapy support for adults aged 50 and older with a chronic vestibular syndrome in general practice: three armed randomised controlled trial. BMJ 367:15922

26. Kolovos S, Kenter RM, Bosmans JE, Beekman AT, Cuijpers $\mathrm{P}$, Kok RN et al (2016) Economic evaluation of Internet-based problem-solving guided self-help treatment in comparison with enhanced usual care for depressed outpatients waiting for faceto-face treatment: a randomized controlled trial. J Affect Disord 200:284-292

27. Andersson G, Cuijpers P, Carlbring P, Riper H, Hedman E (2014) Guided Internet-based vs. face-to-face cognitive behavior therapy for psychiatric and somatic disorders: a systematic review and meta-analysis. World Psychiatry 13(3):288-295

28. Karyotaki E, Ebert DD, Donkin L, Riper H, Twisk J, Burger S et al (2018) Do guided internet-based interventions result in clinically relevant changes for patients with depression? An individual participant data meta-analysis. Clin Psychol Rev 63:80-92

29. Waldren SE, Agresta T, Wilkes T (2017) Technology tools and trends for better patient care: beyond the EHR. Fam Pract Manag 24(5):28-32

30. Han HR, Gleason KT, Sun CA, Miller HN, Kang SJ, Chow S et al (2019) Using patient portals to improve patient outcomes: systematic review. JMIR Hum Fact 6(4):e15038

31. Muller KI, Alstadhaug KB, Bekkelund SI (2016) Acceptability, feasibility, and cost of telemedicine for nonacute headaches: a randomized study comparing video and traditional consultations. J Med Internet Res 18(5):e140

32. Allena M, Cuzzoni MG, Tassorelli C, Nappi G, Antonaci F (2012) An electronic diary on a palm device for headache monitoring: a preliminary experience. J Headache Pain 13(7):537-541

33. Bandarian-Balooch S, Martin PR, McNally B, Brunelli A, Mackenzie S (2017) Electronic-diary for recording headaches, triggers, and medication use: development and evaluation. Headache J Head Face Pain 57(10):1551-1569

34. Barmettler G, Brawn J, Maleki N, Scrivani S, Burstein R, Becerra L et al (2015) A new electronic diary tool for mapping and tracking spatial and temporal head pain patterns in migraine. Cephalalgia 35(5):417-425

35. Berengueres J, Cadiou $\mathrm{F}$ (eds) Migraine factors as reported by smartphone users. In: 2016 38th Annual international conference of the IEEE engineering in medicine and biology society (EMBC); 2016: IEEE

36. Cronin AH, Sterzi R, Perteghella D, Agostoni EC, Frediani F (2018) Can the app HeadApp! ${ }^{\circledR}$ be useful in migraine epidemiology? A proposal of a digital algorithm for migraine criteria. Neurol Sci 39(1):141-142

37. Filipi JM, Khairat S (2013) Tracking and visualizing chronic headache trends through the use of linked mobile and desktop websites. Stud Health Technol Inform 190:45-47

38. Giffin NJ, Ruggiero L, Lipton RB, Silberstein SD, Tvedskov JF, Olesen J et al (2003) Premonitory symptoms in migraine: an electronic diary study. Neurology 60(6):935-940

39. Giffin NJ, Lipton RB, Silberstein SD, Olesen J, Goadsby PJ (2016) The migraine postdrome: an electronic diary study. Neurology 87(3):309-313

40. Goldberg J, Wolf A, Silberstein S, Gebeline-Myers C, Hopkins M, Einhorn K et al (2007) Evaluation of an electronic diary as a diagnostic tool to study headache and premenstrual symptoms in migraineurs. Headache 47(3):384-396

41. Houle TT, Turner DP, Golding AN, Porter JA, Martin VT, Penzien DB et al (2017) Forecasting individual headache attacks using perceived stress: development of a multivariable prediction model for persons with episodic migraine. Headache J Head Face Pain 57(7):1041-1050

42. Huguet A, McGrath PJ, Wheaton M, Mackinnon SP, Rozario S, Tougas ME et al (2015) Testing the feasibility and psychometric properties of a mobile diary (myWHI) in adolescents and young adults with headaches. JMIR mHealth and uHealth 3(2):e39

43. Kikuchi H, Yoshiuchi K, Yamamoto Y, Komaki G, Akabayashi A (2012) Diurnal variation of tension-type headache intensity and exacerbation: an investigation using computerized ecological momentary assessment. Biopsychosoc Med 6(1):18

44. Kikuchi H, Yoshiuchi K, Ando T, Yamamoto Y (2015) Influence of psychological factors on acute exacerbation of tension-type headache: investigation by ecological momentary assessment. J Psychosom Res 79(3):239-242 
45. Van Diest AMK, Ramsey R, Aylward B, Kroner JW, Sullivan SM, Nause K et al (2016) Adherence to biobehavioral recommendations in pediatric migraine as measured by electronic monitoring: the adherence in migraine (AIM) study. Headache 56(7):1137-1146

46. Moloney MF, Aycock DM, Cotsonis GA, Myerburg S, Farino C, Lentz M (2009) An Internet-based migraine headache diary: issues in Internet-based research. Headache 49(5):673-686

47. Palermo TM, Valenzuela D, Stork PP (2004) A randomized trial of electronic versus paper pain diaries in children: impact on compliance, accuracy, and acceptability. Pain 107(3):213-219

48. Park J-W, Chu MK, Kim J-M, Park S-G, Cho S-J (2016) Analysis of trigger factors in episodic migraineurs using a smartphone headache diary applications. PLoS One. 11(2):1-13

49. Park J-W, Cho S-J, Park S-G, Chu MK (2018) Circadian variations in the clinical presentation of headaches among migraineurs: a study using a smartphone headache diary. Chronobiol Int 35(4):546-554

50. Seng EK, Prieto P, Boucher G, Vives-Mestres M (2018) Anxiety, incentives, and adherence to self-monitoring on a mobile health platform: a naturalistic longitudinal cohort study in people with headache. Headache J Head Face Pain 58(10):1541-1555

51. Sorbi MJ, Mak SB, Houtveen JH, Kleiboer AM, van Doornen LJ (2007) Mobile Web-based monitoring and coaching: feasibility in chronic migraine. J Med Internet Res 9(5):e38

52. Tassorelli C, Jensen R, Allena M, De Icco R, Katsarava Z, Miguel Lainez $\mathrm{J}$ et al (2017) The added value of an electronic monitoring and alerting system in the management of medicationoveruse headache: a controlled multicentre study. Cephalalgia 37(12):1115-1125

53. Thomas JG, Pavlovic J, Lipton RB, Roth J, Rathier L, O'Leary KC et al (2016) Ecological momentary assessment of the relationship between headache pain intensity and pain interference in women with migraine and obesity. Cephalalgia 36(13):1228-1237

54. Vo P, Paris N, Bilitou A, Valena T, Fang J, Naujoks C et al (2018) Burden of migraine in Europe using self-reported digital diary data from the migraine Buddy ${ }^{\odot}$ application. Neurol Ther 7(2):321-332

55. Huguet A, Stinson J, MacKay B, Watters C, Tougas M, White M et al (2014) Bringing psychosocial support to headache sufferers using information and communication technology: lessons learned from asking potential users what they want. Pain Res Manage 19(1):e1-e8

56. Kleiboer A, Sorbi M, Mérelle S, Passchier J, van Doornen L (2009) Utility and preliminary effects of online digital assistance
(ODA) for behavioral attack prevention in migraine. Telemed J E Health 15(7):682-690

57. Law EF, Beals-Erickson SE, Noel M, Claar R, Palermo TM (2015) Pilot randomized controlled trial of Internet-delivered cognitive-behavioral treatment for pediatric headache. Headache 55(10):1410-1425

58. Sorbi MJ, Balk Y, Kleiboer AM, Couturier EG (2017) Follow-up over 20 months confirms gains of online behavioural training in frequent episodic migraine. Cephalalgia 37(3):236-250

59. Sorbi MJ, van der Vaart R (2010) User acceptance of an Internet training aid for migraine self-management. J Telemed Telecare 16(1):20-24

60. Devineni T, Blanchard EB (2005) A randomized controlled trial of an internet-based treatment for chronic headache. Behav Res Ther 43(3):277-292

61. Minen MT, Jalloh A, Ortega E, Powers SW, Sevick MA, Lipton RB (2019) User design and experience preferences in a novel smartphone application for migraine management: a think aloud study of the RELAXaHEAD application. Pain Med 20(2):369-377

62. Müller KI, Alstadhaug KB, Bekkelund SI (2016) Acceptability, feasibility, and cost of telemedicine for nonacute headaches: a randomized study comparing video and traditional consultations. J Med Internet Res 18(5):e140

63. Müller KI, Alstadhaug KB, Bekkelund SI (2017) A randomized trial of telemedicine efficacy and safety for nonacute headaches. Neurology 89(2):153-162

64. Müller KI, Alstadhaug KB, Bekkelund SI (2017) Headache patients' satisfaction with telemedicine: a 12-month follow-up randomized non-inferiority trial. Eur J Neurol 24(6):807-815

65. Qubty W, Patniyot I, Gelfand A (2018) Telemedicine in a pediatric headache clinic: a prospective survey. Neurology 90(19):e1702-e1705

66. Sciamanna CN, Nicholson RA, Lofland JH, Manocchia M, Mui S, Hartman CW (2006) Effects of a Website designed to improve the management of migraines. Headache 46(1):92-100

67. Raieli V, Loiacono C, Messina LM, Correnti E, Brighina F (2018) Is a digital platform useful in headache training? A 4-year Italian experience. Neurol Sci 39(12):2223-2224

68. Ramsey RR, Holbein CE, Powers SW, Hershey AD, Kabbouche MA, O'Brien HL et al (2018) A pilot investigation of a mobile phone application and progressive reminder system to improve adherence to daily prevention treatment in adolescents and young adults with migraine. Cephalalgia 38(14):2035-2044 